\title{
PROTECTIVE EFFECT OF BEE PROPOLIS AGAINST ANTI-TUBERCULOSIS DRUGS (RIFAMPICIN AND ISONIAZID)-INDUCED HEMATOLOGICAL TOXICITY IN SPRAGUE DAWLEY RATS
}

\author{
UMESH BHARTI ${ }^{1}$, NEELIMA R KUMAR ${ }^{2}$, JASPREET KAUR ${ }^{3}$
}

${ }^{1}$ Department of Zoology, PG Govt. College for Girls, Sector-11, Chandigarh, Punjab, India. ${ }^{2}$ Department of Zoology, Panjab University, Chandigarh, Punjab, India. ${ }^{3}$ Department of Biotechnology, UIET, Panjab University, Chandigarh, Punjab, India. Email: dbhv90@gmail.com

Received: 01 November 2016, Revised and Accepted: 16 December 2016

\section{ABSTRACT}

Objective: Protective effect of bee propolis against anti-tuberculosis (TB) drugs (rifampicin and isoniazid)-induced hematological toxicity in Sprague Dawley (SD) rats.

Methods: Experimental male SD rats weighing 180 \pm 20 g were randomly assigned into eight groups (n=6), the Group 1 served as control; Group 2 received $200 \mathrm{mg}$ bee propolis/kg body weight; Groups 3, 5, and 7 were treated with drugs $100 \mathrm{mg}$ rifampicin/kg body weight, $50 \mathrm{mg}$ isoniazid/kg body weight, and $100 \mathrm{mg}$ rifampicin $+50 \mathrm{mg}$ isoniazid/kg body weight, respectively. Groups 4,6 , and 8 were treatment groups receiving $200 \mathrm{mg}$ bee propolis/ $\mathrm{kg}$ body weight $+100 \mathrm{mg}$ rifampicin/ $\mathrm{kg}$ body weight, $200 \mathrm{mg}$ bee propolis/ $\mathrm{kg}$ body weight $+50 \mathrm{mg}$ isoniazid/ $\mathrm{kg}$ body weight, and $200 \mathrm{mg}$ bee propolis/kg body weight+100 mg rifampicin $+50 \mathrm{mg}$ isoniazid/kg body weight, respectively. All the treatments were given for 30 days, and then, the rats were sacrificed under light esthesia by cervical dislocation and blood was collected for physiological studies.

Results: Bee propolis supplementation (200 mg/kg body weight) showed increased level of hemoglobin with respect to rifampicin (15.45\%), isoniazid (11.34\%), and rifampicin plus isoniazid (5.04\%) administered groups after 30 days of treatment. Moreover, the decreased level of red blood cell count and white blood cell count by anti-TB drugs rifampicin, isoniazid, and rifampicin plus isoniazid together was also elevated in treatment group with bee propolis.

Conclusion: Coadministration of propolis (200 mg bee propolis/kg body weight) with drugs helped modulate the toxic effects by restoring tested values to near normal.

Keywords: Propolis, Rifampicin, Isoniazid, Hemoglobin, Red blood cell count, White blood cell count.

(C) 2017 The Authors. Published by Innovare Academic Sciences Pvt Ltd. This is an open access article under the CC BY license (http://creativecommons. org/licenses/by/4. 0/) DOI: http://dx.doi.org/10.22159/ajpcr.2017.v10i3.15991

\section{INTRODUCTION}

Propolis (bee glue) by honey bees from the bark of the trees and flower buds is an adhesive, resinous substance which is transformed with bee wax and salivary secretions and used by honey bees to seal crevices in their hive and prevent the entry of intruders. Bee propolis is rich in phenols, tannins, polysaccharides, flavonoids, terpenes, aromatic acids, and aldehydes. Propolis has imperative pharmacological properties which can be used for a wide range of purposes as anti-inflammatory, antioxidant, and antibacterial agents [1]. Various plant derived drugs (such as Pongamia pinnata, Emblica officinalis, and Rubia cordifolia) were reported to be the best alternative drug for the anti-tuberculosis (TB) drug-induced toxicity [2,3].

TB is a communicable disease and is a major global health problem. In 2014, 9.6 million new TB cases were reported, out of which 5.4 million were men, 3.2 million were women, and 1.0 million were children. There were 1.5 million TB deaths [4]. Drugs used for the treatment of TB have been reported to cause major adverse reactions and significant morbidity leading to a compromised treatment regimen. Side effects such as hepatitis, dyspepsia, exanthema, and arthralgia were responsible for termination of therapy in up to $23 \%$ of patients during the intensive phase [5]. Several studies have reported that leukopenia, eosinophilia, hemolytic anemia along with hepatotoxicity, fatigue, dizziness, headache, and dyspnea, occurred after rifampicin and isoniazid administration [6] (Baciewicz et al., 2008). Regular education and monitoring of patients were also required to control the disease in developing nations [7]. The aim of this study was to evaluate the protective effect of dietary bee propolis supplementation against toxicity induced by anti-TB drugs rifampicin and isoniazid in Sprague Dawley (SD) rats.

\section{METHODS}

Experimental animals

Male SD rats of body weight in the range of $180 \pm 20 \mathrm{~g}$ were obtained from the central animal house of Panjab University, Chandigarh, vide institutional animal ethics committee approval letter no. PU/IAEC/2013/18. Animals were kept in polypropylene cages bedded with rice husk in 12 hrs light/dark cycle under hygienic conditions. They were fed with standard pellet feed and water ad libitum.

Collection and preparation of bee propolis extract

Bee propolis was collected from Langstroth bee hives maintained in an apiary at Majri village near Old Panchkula, Haryana. Ethanolic extract of propolis was prepared.

\section{Drugs}

Rifampicin and isoniazid drugs were purchased from Himedia.

\section{Experimental protocol}

The animals (male SD) were randomly assigned into eight groups of six rats each and treated as follows:

- Group A: Control group with normal water

- Group B: $200 \mathrm{mg}$ bee propolis/kg body weight

- Group C: $100 \mathrm{mg}$ rifampicin/kg body weight

- Group D: $200 \mathrm{mg}$ bee propolis/kg body weight+100 mg rifampicin/kg body weight 
- Group E: $50 \mathrm{mg}$ isoniazid/kg body weight

- Group F: $200 \mathrm{mg}$ bee propolis/kg body weight+50 mg isoniazid/kg body weight

- Group G: $100 \mathrm{mg}$ rifampicin+50 mg isoniazid/kg body weight

- Group H: $200 \mathrm{mg}$ bee propolis/kg body weight+100 mg rifampicin $+50 \mathrm{mg}$ isoniazid/kg body weight.

Oral gavages using a metal oropharyngeal cannula and syringe were employed in the administration of the bee propolis extract, rifampicin, and isoniazid once daily for 30 days. The animals were sacrificed by cervical dislocation after 30 days of treatment.

\section{Blood collection}

Blood samples were taken from each rat by terminal bleeding from the vena cava with syringe rinsed with EDTA and transferred into a sterile EDTA container

\section{Hemoglobin estimation}

Principle

Hemoglobin reacts with $\mathrm{N} / 10 \mathrm{HCl}$ and gets converted into golden brown acid hematin. The intensity of color depends on the amount of hemoglobin in the blood. Sahli's hemoglobin meter was used to estimate hemoglobin $(\mathrm{g} / \mathrm{dl})[8]$.

\section{Red blood cell count (RBC count)}

Principle

Blood is diluted 200 times with the help of RBC diluting fluid (Hayem's solution). Neubauer hemocytometer was used to count the number of RBCs under light microscope [8]. The final result was expressed as the number of cells per cumm of blood using the formula below:

RBC count $=\frac{\begin{array}{l}\text { Number of redblood cellscounted } \\ \times \text { Dilution factor } \times 4000\end{array}}{80(\text { Number of smallsquarescounted })}$

\section{Total white blood cell (WBC) count}

Principle

The blood is diluted 20 times with the help of WBC diluting fluid (Turk's Fluid). Neubauer hemocytometer was used to count WBC's under light microscope [8]. The number of cells present in the 4 corner areas (1 $\mathrm{mm}^{2}$ each) was counted.

$$
\text { WBCcount }=\frac{\text { Number of cells counted } \times \text { Dilution factor } \times 10}{4(\text { Number of } 1 \text { squaresml.counted })}
$$

\section{Statistical analysis}

Data were presented as mean \pm standard deviation and analyzed using one-way analysis of variance. $\mathrm{p}<0.05$ were considered statistically significant.

\section{RESULTS AND DISCUSSIONS}

\section{Effect of bee propolis on hemoglobin}

Hemoglobin level of the animals given bee propolis extract $(200 \mathrm{mg} / \mathrm{kg}$ body weight) was $14.52 \pm 0.17$, which was lower than the control group $(15.1 \pm 0.18)$ at $p<0.005$. A significant decrease $(23.70 \%)$ in the level of hemoglobin was observed with $(100 \mathrm{mg} / \mathrm{kg}$ body weight) rifampicin, there was $18.34 \%$ decrease in isoniazid $(50 \mathrm{mg} / \mathrm{kg}$ body weight), and $12.05 \%$ decrease in combination of rifampicin $(100 \mathrm{mg} / \mathrm{kg}$ body weight) plus isoniazid ( $50 \mathrm{mg} / \mathrm{kg}$ body weight)-treated groups.

When, however, the treatment was supplemented with bee propolis (200 mg/kg body weight) drastic increase was noticed with respect to rifampicin (15.45\%) $100 \mathrm{mg} / \mathrm{kg}$ body weight, isoniazid (11.34\%) $50 \mathrm{mg} / \mathrm{kg}$ body weight, and rifampicin plus isoniazid (5.04\%) $100 \mathrm{mg} / \mathrm{kg}+50 \mathrm{mg} / \mathrm{kg}$ body weight administered groups after 30 days of treatment. The results were expressed as mean \pm standard deviation $(\mathrm{n}=6)$. The data were analyzed using one-way analysis of variation (Fig. 1).

\section{Effect of bee propolis on RBC count}

The RBC count of control rat was $8.15 \pm 0.21$ million/cumm. When anti-TB drugs were given, significant decrease was observed, which was $4.19 \%$ with rifampicin, $4.05 \%$ with isoniazid, and $3.81 \%$ with rifampicin plus isoniazid together. On treatment with bee propolis at a dose of $200 \mathrm{mg} / \mathrm{kg}$ body weight with rifampicin $(100 \mathrm{mg} / \mathrm{kg}$ body weight), the level were increased to $7.39 \pm 0.14 \mathrm{million} / \mathrm{cumm}$, with isoniazid ( $50 \mathrm{mg} / \mathrm{kg}$ body weight) $7.65 \pm 0.21$ million/cu $\mathrm{mm}$ and with rifampicin and isoniazid $(100 \mathrm{mg} / \mathrm{kg}+50 \mathrm{mg} / \mathrm{kg}$ body weight) together red blood cell count was $7.735 \pm 0.21$ million/cumm.

Rise in RBC count on treatment with bee propolis was statistically significant at $p \leq 0.05$ with respect to rifampicin, isoniazid, and rifampicin and isoniazid together as shown in the Fig. 2. The results were expressed as mean \pm standard deviation $(n=6)$. The data were analyzed using one-way analysis of variation.

\section{Effect of bee propolis on WBC count}

The total leukocyte count (TLC) for normal rat was found to be $18925 \pm 250$. Leukopenia was observed in drug-treated rats with decrease of $37.78 \%$ (rifampicin), $26.81 \%$ (isoniazid), and $37.51 \%$ (rifampicin and isoniazid together).

After 30 days of treatment with $20 \mathrm{mg} / \mathrm{kg}$ body weight of bee propolis significant increase of $22.92 \%$ ( $100 \mathrm{mg} / \mathrm{kg}$ body weight of rifampicin), $22.90 \%$ (50 mg/kg body weight of isoniazid), and $45.87 \%$ (rifampicin, $100 \mathrm{mg} / \mathrm{kg}$ body weight + isoniazid $50 \mathrm{mg} / \mathrm{kg}$ body weight together) was seen in WBC count. The data were statistically significant at $\mathrm{p} \leq 0.05$ as shown in Fig. 3. The results were expressed as mean \pm standard deviation $(\mathrm{n}=6)$. The data were analyzed using one-way analysis of variation.

TB is a leading health problem in developing countries and is the major cause of death worldwide (almost $40 \%$ of the world's TB cases). Rifampicin and isoniazid are important first-line drugs used against TB [4]. Since the drugs used in treatment of TB have been reported to show toxic side effects (hypersensitivity reactions, hepatitis, acute interstitial nephritis neuropsychiatric, hepatic, and gastrointestinal problems in patients with chronic renal failure) [9], studies have been performed to attempt to reduce the toxicity using various herbal products such as vitamin E [9], silymarin [10], ocimum [11], bee pollen [8], and garlic [12]. The polyphenolic compounds present in propolis [13] have protective effect for the RBC cell membrane [14]. Administration of propolis to diabetic mice significantly elevated hematological parameters such as the total number of red blood cells,

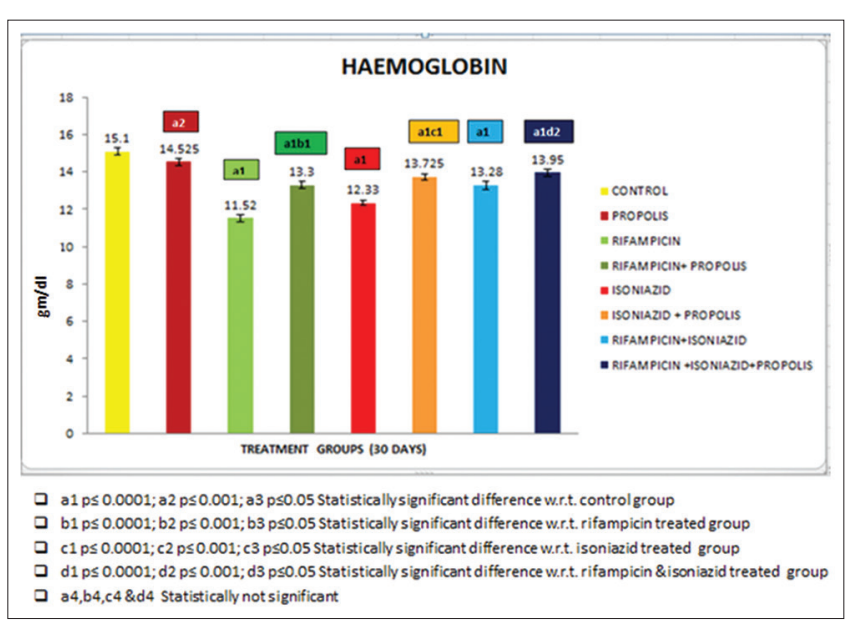

Fig. 1: Effect on hemoglobin level in eight treatment groups $(n=6)$ (mean \pm standard deviation) 


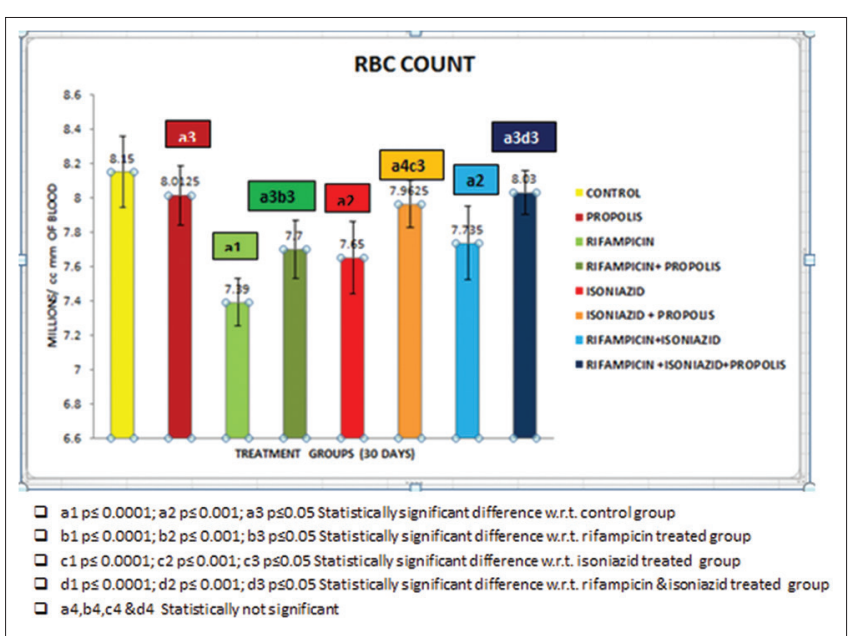

Fig. 2: Effect on red blood cell count in different treatment groups $(n=6)$ (mean \pm standard deviation)

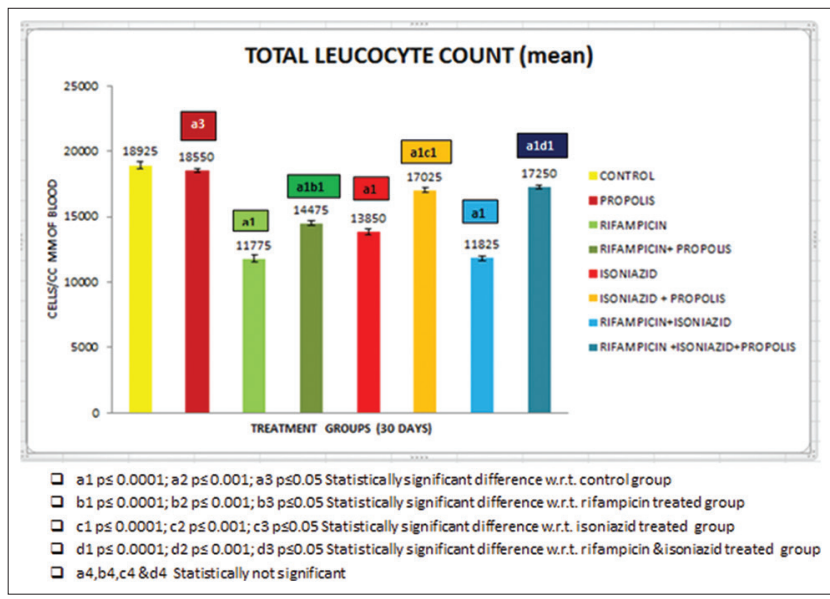

Fig. 3: Effect on total leukocyte count in different treatment groups $(n=6)(m e a n \pm s t a n d a r d ~ d e v i a t i o n)$

hemoglobin, and hematocrit level [15]. Antioxidant and free-radical scavenging properties of propolis [16] due to the presence of flavonoids and phenolic antioxidants were responsible for protective effect against anti-TB drugs. Increased hemoglobin level, RBC count and WBC count revealed in the present study therapeutic properties of propolis against anti-TB drugs rifampicin and isoniazid toxicity.

\section{CONCLUSION}

The generation of hematological response was calculated through hemoglobin estimation, RBC count and TLC in different groups of SD rats. Anemia was detected in anti-TB drug-treated animals. There was severe decline in hemoglobin count, RBC count, and WBC count when animals were treated with rifampicin, isoniazid, and rifampicin and isoniazid in combination. On supplementing bee propolis with anti-TB drugs, significant escalation in the level of hemoglobin, RBC count and WBC count were recorded. The treatment with propolis could recover cellular membrane and organ functioning more profoundly, thereby maintaining all hematological parameters near normal values. This supports the hypothesis that bee propolis shows protective effect by normalizing the levels of treated blood parameters.

\section{REFERENCES}

1. Banskota AH, Tezuka Y, Kadota S. Recent progress in pharmacological research of propolis. Phytother Res 2001;15(7):561-71

2. Tasduq SA, Kaisar P, Gupta DK, Kapahi BK, Jyotsna S, Maheshwari HS, et al. Protective effect of a 50\% hydroalcoholic fruit extract of Emblica officinalis against anti-tuberculosis drugs induced liver toxicity. Phytother Res 2005;19(3):193-7.

3. Rajeshkumar S, Kayalvizhi D. Antioxidant and hepatoprotective effect of aqueous and ethanolic extracts of important medicinal plant Pongamiapinnata (Family: Leguminoseae). Asian J Pharm Clin Res 2015;8(5):67-70.

4. WHO. Global Tuberculosis Report 2015. Geneva: WHO; 2015.

5. Schaberg T, Rebhan K, Lode H. Risk factors for side-effects of isoniazid, rifampicin and pyrazinamide in patients hospitalized for pulmonary tuberculosis. Eur Respir J 1996;9(10):2026-30.

6. Baciewicz AM, Chrisman CR, Finch CK, Self TH. Update on rifampin and rifabutin drug interactions. Am J Med Sci 2008;335(2):126-36.

7. Vijayalakshmi A, Thanmayi G, Jayakumari S. A prospective study on abnormal liver function test patterns in patients receiving antituberculosis therapy. Asian J Pharm Clin Res 2016;9(5):136-9.

8. Bharti U, Neelima RK, Kaur J. Ameliorating effect of bee pollen against anti-tuberculosis drugs (rifampicin and isoniazid) induced toxicity on haematology of Sprague Dawley rats. Int J Sci Res 2016;5(4):2077-82.

9. Yee D, Valiquette C, Pelletier M, Parisien I, Rocher I, Menzies D. Incidence of serious side effects from first-line antituberculosis drugs among patients treated for active tuberculosis. Am J Respir Crit Care Med 2003;167(11):1472-7.

10. Eminzade S, Uras F, Izzettin FV. Silymarin protects liver against toxic effects of anti- tuberculosis drugs in experimental animals. Nutr Metab(Lond) 2008;5:1-8.

11. Ubaid RS, Anantrao KM, Jaju JB, Mateenuddin M. Effect of Ocimum sanctum (OS) leaf extract on hepatotoxicity induced by antitubercular drugs in rats. Indian $\mathrm{J}$ Physiol Pharmacol 2003;47(4):465-70.

12. Nasiru A, Hafsat IG, Sabo AA. Effect of anti- tuberculosis drugs coadministered with garlic homogenate on rat liver enzymes. IPCBEE 2012;40:96-8.

13. Kalia P, Kumar NR, Harjai K. Phytochemical screening and antibacterial activity of different extracts of propolis. Int J Pharm Biol Res 2013;3(6):219-22

14. Youdim KA, Shukitt-Hale B, Mackinnon S, Kalt W, Joseph JA. Polyphenolics enhance red blood cell resistance to oxidative stress: In vitro and in vivo. Biochim Biophys Acta 2000;1523:117-22.

15. Oršolić N, Sirovina D, Končić MZ, Lacković G, Gregorović G. Effect of Croatian propolis on diabetic nephropathy and liver toxicity in mice. BMC Complement Alternat Med 2012;12:117.

16. Basnet $\mathrm{P}$, Matsuno $T$, Neidlein R. Potent free radical scavenging activity of propol isolated from Brazilian propolis. Z Naturforsch C 1997;52(11-12):828-33. 